\title{
Dosslê
}

\section{Orientação educacional e mediação de conflitos: a busca por uma escola restaurativa ${ }^{1}$}

\author{
Maria Luiza da Costa Rosa Souza ${ }^{2}$ \\ Ana Maria Ribas ${ }^{3}$
}

Resumo: Os conflitos perpassam as relações humanas; no espaço escolar, normalmente cabe ao orientador educacional o trato dos conflitos entre estudantes e seus pares, professores, família e escola. Assim, a intenção desta pesquisa é identificar a contribuição do orientador educacional na resolução e mediação, de forma não violenta, dos conflitos escolares de uma escola punitiva para uma escola restaurativa. Para isso, realizou-se revisão bibliográfica com o enfoque no entendimento dos processos de mediação e das práticas restaurativas e sua aplicabilidade pelo orientador educacional na escola. Os resultados indicaram que o orientador educacional está apto a auxiliar a escola na realização da transição dos modelos punitivos, no que se refere à resolução dos conflitos, por meio da mediação e das práticas restaurativas.

Palavras-chave: Orientador educacional. Conflitos escolares. Escola restaurativa.

\section{Educational orientation and conflict mediation: the search for a restorative school}

\begin{abstract}
Conflicts permeate human relations, and in school, dealing with conflicts between students and their peers, teachers, family and school, usually falls to the educational supervisor. The intention of this research is to identify the contribution of the educational advisor in the non-violent resolution and mediation of school conflicts for the transition from a punitive school to a restorative school. There for, a bibliographic review was conducted with the focus on understanding the processes of mediation and restorative practices and their applicability by the educational supervisor in the school. The results indicated that the educational supervisor is able to help the school to carry out the transition of the punitive models in the resolution of conflicts through mediation and restorative practices.

Keywords: Educational advisor. School conflicts. Restorative school.
\end{abstract}

\section{Orientación educacional y mediación de conflictos: la búsqueda de una escuela restaurativa}

Resumen: Los conflictos atraviesan las relaciones humanas y, en el espacio escolar, la solución de conflictos entre estudiantes y sus colegas, profesores, familia y escuela, 
normalmente, es una responsabilidad del orientador educacional. Así, la intención de este estudio es identificar la contribución del orientador educacional en la solución y mediación, de forma no violenta, de los conflictos escolares, pasando de una escuela punitiva para una escuela restaurativa. Para ello, se realizó una revisión bibliográfica con el enfoque en el entendimiento de los procesos de mediación y de las prácticas restaurativas y su aplicabilidad por parte del orientador educacional en la escuela. Los resultados indicaron que el orientador educacional está preparado para auxiliar la escuela a realizar la transición de los modelos punitivos, en relación a la solución de los conflictos, por medio de la mediación y de las prácticas restaurativas.

Palabras clave: Orientador educacional. Conflictos escolares. Escuela restaurativa.

\section{Introdução}

O ambiente escolar acolhe, entre seus muros, uma diversidade de pessoas com aspirações diferentes, contribuindo para que os conflitos surjam, com certa frequência, nas relações entre estudantes e seus pares, professores e alunos, professores e colegas de trabalho ou, ainda, entre escola e família.

É prática que as situações de conflito, especialmente entre os estudantes, sejam encaminhadas ao orientador educacional, o qual é um dos profissionais listados na Lei no 12.014 de 2009 como:

Profissionais da educação básica escolar os que, nela estando em efetivo exercício e tendo sido formados em cursos reconhecidos, são: trabalhadores em educação portadores de diploma de pedagogia, com habilitação em administração, planejamento, supervisão, inspeção e orientação educacional, bem como com títulos de mestrado ou doutorado nas mesmas áreas (BRASIL, 2009).

Caso o orientador educacional não elabore um planejamento para resolução de conflitos de forma não violenta e não capacite a comunidade escolar para lidar com eles, a sua prática diária se tornará reativa diante das demandas também diárias que lhes são encaminhadas. Por isso, há de se analisar de que maneira o orientador educacional pode orientar a comunidade escolar no manejo dos conflitos que surgem, adotando uma cultura restaurativa e não punitiva. Todavia, tradicionalmente, há, por parte dos demais educadores, uma cobrança para que o orientador educacional aplique as punições aos estudantes indisciplinados, bem como uma tendência a desvalorizar as práticas restaurativas.

Entende-se por práticas restaurativas ações que consistem em centralizar o foco na pessoa (o estudante, o professor ou os pais). A pessoa e suas expectativas devem estar sempre em vista, buscando a interação entre as partes, o desenvolvimento e o exercício da disciplina como autodomínio a partir de uma visão de que os conflitos são oportunidades de crescimento (CECCON et al., 2009). 
É, portanto, diante desse contexto que se propõe realizar esta revisão, tendo como eixo norteador a seguinte problemática: de que forma a práxis do orientador educacional pode contribuir para que conflitos escolares sejam resolvidos de forma não violenta e que se passe de uma escola punitiva para uma escola restaurativa?

Tem-se por objetivo geral identificar a contribuição do orientador educacional na resolução e mediação, de forma não violenta, dos conflitos escolares de uma escola punitiva para uma escola restaurativa. Para alcançar esse objetivo maior, pretende-se descrever os conflitos escolares mais recorrentes, analisar a mediação de conflitos escolares pelo orientador educacional e propor ações para que se passe de uma escola punitiva para uma escola restaurativa.

O princípio da pesquisa fundamenta-se na hipótese de que o orientador educacional detém conhecimento necessário para mediar e resolver conflitos escolares de forma não violenta, pois compreende que os conflitos são inerentes à natureza humana e, portanto, existirão nas relações interpessoais. É importante que se supere a concepção de escola punitiva para uma escola restaurativa.

Aprofundar a temática da mediação de conflitos, estendendo o olhar para as práticas restaurativas, tem sua validade para as ações do orientador educacional, uma vez que os conflitos escolares tendem a exigir desse profissional a capacidade de restaurar o diálogo entre partes instáveis e garantir uma escola segura para que a aprendizagem aconteça e que estudantes, educadores e comunidade sintam-se corresponsáveis pela manutenção do ambiente escolar pacífico e acolhedor.

A metodologia adotada foi a revisão bibliográfica, cujo intuito é responder à problemática por meio de referencial teórico previamente selecionado e já publicado referente ao tema. Estabelecida a situação-problema, buscou-se por publicações de 2006 a 2016, na base de dados Scientific Eletronice Library Online (SciELO), que abordassem a diferença entre conflito e violência, com ênfase em conflitos escolares, o processo de medição dos conflitos escolares e o papel do orientador, a resolução desses conflitos de forma não violenta e as leis que norteiam o trato dos conflitos no espaço escolar.

\section{Conflito e violência: manifestações do cotidiano na vida humana}

Cecília Meirelles (1990), em sua poesia "Ou isto ou aquilo", retrata uma situação humana em que o ato de escolher determinada ação gera o conflito de decisão: "ou guardo o dinheiro e não compro o doce, ou compro o doce e não guardo o dinheiro". E conclui: "mas não consegui entender ainda qual é o melhor: se isto ou aquilo". Parece simples, porém exprime o antagonismo que se pode estabelecer nas relações interpessoais diárias.

Observa-se, cotidianamente, que o conflito surge quando opiniões se divergem, bem como interesses são frustrados diante da intromissão alheia. O 
conflito é característico da natureza humana, definido como situações que "pessoas unidas por interdependência buscam satisfazer suas necessidades e interesses de formas diferentes e, por isso, experimentam a interferência um dos outros em seus objetivos" (GARSTONS; WELLMAN, 1999 apud CECCON et al., 2009, p. 29). As palavras de Chrispino (2007, p. 15) complementam essa conceituação, quando diz que "[...] conflito é toda opinião divergente ou maneira de ver ou interpretar algum conhecimento".

$\mathrm{O}$ ato conflituoso se manifesta, com frequência, quando recursos naturais, tempo e espaços são utilizados. A princípio, o conflito não é ruim ou bom, mas a resposta dada a ele poderá receber a denotação negativa ou positiva.

Cada pessoa carrega em si um universo de individualidade, de modo que, diante de um conflito, haverá uma diversidade de reações. Nascimento et al. (2007) elencam quatro possibilidades de reações por causa de uma situação discordante:

- Competição: haverá um ganhador.

- Colaboração: há a percepção de que não há um ganhador.

- Compromisso: se todos não ganharem, visa a uma troca de favores. Ganha-se algo se der alguma coisa em troca.

- Evitação: pressupõe distanciamento a todo custo do conflito. Pode ser negativa, quando provoca conformidade diante dos problemas, e positiva, quando a pessoa espera o melhor momento para buscar a resolução do conflito.

Um pressuposto para se gerenciar adequadamente um conflito é a existência de diálogo. Diálogo, como afirma Freire (2014, s/p), nada mais é “"...] que uma relação horizontal de A com B”. Em outras palavras, por meio do diálogo, o poder em exercício está equilibrado e nenhuma das partes se submete à outra. É, portanto, a capacidade de dialogar que favorece o equilíbrio entre partes envolvidas em determinada situação, tornando possível a resolução pacífica do conflito.

Apesar da existência de diálogo, a situação conflitante pode se tornar instável, e isso ocorre justamente porque há caos e ordem, forças concomitantes nas relações interpessoais. O perigo se instaura a partir do momento em que "um poder prepondera e rompe o equilíbrio" (CECCON et al., 2009, p. 37), passando-se, assim, à violência.

O termo "violência" traz, em sua origem epistemológica, o sentido de força. No entanto, a força passa a constituir ato violento quando ultrapassa os limites acordados histórica e socialmente. Diferentemente do conflito, violência não é inerente ao ser humano, mas uma construção social. Torna-se imperativa em ambientes nos quais não é mais possível fazer valer o diálogo (CECCON et al., 2009). 
Conceitua-se violência como uso da força de forma direta ou indireta, no intuito de prejudicar um indivíduo ou grupo em sua integridade física ou psíquica, seja em suas propriedades, seja em suas participações simbólicas. Caracteriza-se como o mais elevado desrespeito e desconsideração para com outro, implicando não só o uso da força física, mas a possibilidade ou ameaça de usá-la (CECCON et al., 2009).

Violência também é uma resposta a um conflito mal manejado, que não foi gerenciado de forma correta em tempo hábil. Nesse aspecto, vale reforçar que a passividade também se configura como uma forma de violência para com o outro, pois, ao fechar voluntariamente os olhos diante de uma situação de violência, o indivíduo ou grupo corrobora a perpetuação das práticas de violência.

Uma forma de se prevenir da violência é dar atenção à resolução dos conflitos, até mesmo aos menores do dia a dia, como a disputa por uma vaga de estacionamento, passando a questões mais sérias, como distribuição mais justa de renda e alimento, água, remédio.

\section{Conflitos escolares}

Nos espaços escolares, os conflitos se manifestam quase que cotidianamente, provenientes das situações comuns do próprio ambiente escolar, isto é, a tarefa de ensinar é permeada por tensões entre professores e alunos, famílias e escola, currículo e políticas educacionais (CHRISPINO, 2007).

Sabe-se que a escola está situada em contexto específico e, dessa forma, sofre com a pressão em forma de conflito e violência, gerados externamente aos seus muros e cujas causas podem ser originadas por fatores socioeconômicos, políticos-organizacionais e até culturais. Ceccon et al. (2009, p. 55) elencam seis causas de conflito e até violência gerada na própria escola advinda da:

1) Dificuldade de criar vínculos e fortalecer sentimentos de conexão e pertencimento.

2) Desconhecimento por parte dos educadores, funcionários, alunos, familiares, dos fatores externos e internos que contribuem para as violências na escola.

3) Falta de normas de convivência que tenham sido coletivamente definidas.

4) Desconhecimento de competências e habilidades necessárias para dialogar e comunicar de forma transparente.

5) Falta ou insuficiência de canais que permitam e estimulem a participação.

6) Abordagem curricular descontextualizada e fragmentada, com matérias que não fazem sentido para os alunos. 
A palavra "pertencer" pressupõe que haja envolvimento, engajamento, cuidado. Assim deve ser com a escola e com cada colaborador, estudante e família. Todo ator educacional deixa suas marcas na história da escola e carrega um pouco dela consigo. O sentimento de fazer parte contribui para que se cuide das relações que nela se estabelecem por meio da valorização do diálogo e da busca de resolver de forma harmoniosa os conflitos.

Chrispino (2007) coloca como uma das causas de conflitos a pouca competência para estabelecer comunicação efetiva, para usar de assertividade, para dialogar, o que está em consonância com Delors et al. (1998), quando salientam que aprender a conviver é desenvolver a habilidade para usar de respeito e de cooperação, construindo bases para uma boa comunicação que levará ao gerenciamento positivo dos conflitos.

Nota-se o quanto administrar os pequenos conflitos é fundamental para se assegurar que estes não terminem em violência, especialmente explorando ao máximo a capacidade da comunidade escolar de dialogar sobre suas expectativas, frustações, resultados, porque é evidente que o diálogo é a via de esclarecimento dos conflitos e prevenção de violência. Retomando Freire (2014), somente o diálogo comunica, uma vez que se sustenta de amor, de humanidade, de esperança, de fé, de confiança.

Nesse aspecto, há de se abordar a questão do bullying, dado que essa é uma forma de conflito que cresce assustadoramente nas escolas. Trata-se de uma violência repetida, intencional e que causa grande sofrimento às vítimas, nas formas física, moral ou psicológica, caracterizadas por uma relação desigual de poder entre as partes, em que uma prepondera sobre a outra.

Em reportagem veiculada pelo Jornal Hoje da Rede Globo de Televisão, no dia 26 de agosto de 2016, foi apresentada uma análise dos dados recolhidos e divulgados pelo Instituto Brasileiro Geográfico e Estatístico (IBGE) sobre a saúde do estudante brasileiro (RAIMUNDI, 2016). O bullying, fundamentado em características da aparência física, é um exemplo de como o fenômeno vem crescendo nas escolas brasileiras.

Ainda sobre o bullying, recorre-se às palavras da Lei $\mathrm{n}^{\circ}$ 13.185, de 6 de novembro de 2015, que considera:

[...] intimidação sistemática (bullying) todo ato de violência física ou psicológica, intencional e repetitivo que ocorre sem motivação evidente, praticado por indivíduo ou grupo, contra uma ou mais pessoas, com o objetivo de intimidá-la ou agredi-la, causando dor e angústia à vítima (BRASIL, 2015, s/p).

Dentro do quadro caracterizado pela lei citada, as ações de bullying, que também são os conflitos escolares mais recorrentes, são variadas e contemplam insultos, xingamentos, agressões físicas, intimidações, comentários maldosos e de cunho pejorativos, fofocas, difamações, calúnias, depreciação virtual, isolamento social, destruição de bens e tantos outros. 
É nesse contexto que figura o profissional da orientação que tem a missão de prevenir, coibir e restaurar o equilíbrio onde há violência e sofrimento causado por ações de bullying, além de desenvolver outras funções, como zelar pela aprendizagem dos estudantes, auxiliar os professores no trabalho com alunos que demonstram dificuldades de aprendizagem e fazer a ponte entre família e escola.

\section{A indisciplina: outra causa de rompimento do equilíbrio escolar}

Aspecto a ser abordado no que tange às práticas da orientação é a ação de ajudar o estudante, ajudar o educador, ajudar a família a compreender o processo educativo e formativo em que se encontra a criança, o adolescente ou o jovem estudante. Todavia, essa relação pode ser comprometida mediante a necessidade de resolver situações de conflitos advindas da conduta indisciplinada dos alunos em sala e nos demais espaços da escola.

Entende-se por indisciplina os comportamentos que não estão em consonância com as regras estabelecidas, como ausentar-se da sala sem a permissão do professor, não trazer o material para a aula, conversar excessivamente e deixar de realizar as atividades propostas, responder em tom desrespeitoso etc.

Vasconcelos (1997) diz que a indisciplina gerada na sala de aula tem sua origem em situações que se estendem para o macrossocial: desvalorização do professor pela sociedade e pelo próprio professor, depreciação da escola, falta de projeto claro em relação à necessidade de estudo, crise da falta de limites. E aponta que o problema da indisciplina é dos educadores, famílias e sociedade, mas nem todos querem assumir o compromisso com a superação.

Ainda fundamentado em Vasconcelos (1997), compreende-se que o professor ou o orientador, sozinhos, não podem mudar o quadro de indisciplina, mas podem mudar o modo como se relacionam com os estudantes, criando um vínculo de pertencimento que previne indisciplinas, posto que atitudes indisciplinadas desgastam as relações entre os sujeitos do processo educativo.

Exemplo disso é quando o professor encaminha ao orientador educacional o aluno que apresenta comportamento indisciplinado. Esse professor, por vezes, não entende quando o orientador trata o aluno com amabilidade, provocando uma reflexão sobre o conflito acontecido em sala em vez de dar uma bronca. Reprimir e punir ainda são as atitudes esperadas pela maior parte dos professores quando dos atos de indisciplina.

Vasconcelos (1997, p. 249) indica a urgência de se superar aquilo que ele chamou de síndrome do encaminhamento, pois entende que "[...] os conflitos entre alunos e professores devem ser enfrentados, antes de mais nada, por eles próprios". Em outras palavras, o próprio professor pode reestabelecer o equilíbrio se for capaz de estabelecer uma conversa ou reflexão com o aluno sobre ato indisciplinado, e não apenas cobrar do orientador uma postura mais rígida no que tange à indisciplina. 
Voltando a Ceccon et al. (2009), depreende-se que há dois caminhos para as escolas no que se refere à indisciplina. O primeiro se configura como círculo vicioso em que, para cada ato indisciplinado, há uma punição e, por causa de sua recorrência, aplica-se uma punição maior, entendida gradualmente como advertência, suspensão, encaminhamento às instâncias judiciais e até a expulsão. Em contrapartida, o segundo caminho aponta para a busca em restabelecer o "equilíbrio perdido, em que, diante de comportamentos que desrespeitam as normas de convivência, busca-se chegar a acordos que incluam o outro, o diferente, em lugar de puni-lo ou excluí-lo” (CECCON et al., 2009, p. 140).

A autora ainda acrescenta que optar pela restauração do equilíbrio não significa não parar o ato indisciplinado ou a manifestação da violência imediatamente, mas chama atenção para o fato de que o educador não é bombeiro para ficar apagando incêndio, isto é, resolvendo conflitos, mas que, justamente por ser educador, deve procurar entender as causas que geram a indisciplina para combatê-la em sua origem. Para isso, o professor pode contar com o orientador educacional.

Nas palavras de Longo e Pereira (2011, p. 187), o orientador é o profissional dentro da escola que deve fazer circular informações qualificadas para potencializar o equilíbrio nas relações interpessoais travadas no espaço escolar, "[...] adotando a prática da reflexão permanente com professores, alunos e pais, a fim de que eles encontrem estratégias para o manejo de problemas recorrentes".

Entende-se que, ao propor a reflexão acerca dos conflitos do cotidiano escolar, o orientador estará pavimentando a disciplina em relações de autonomia construídas em parceria, em laços de pertencimento (CECCON et al., 2009), em que as regras que regerão a vida escolar podem ser elaboradas e acordadas em conjunto, de modo que cada ator do processo educativo se torne sujeito dos seus atos.

Assim, as relações de professores e alunos não devem ser verticalizadas, mas sim de respeito à autoridade delegada ao professor pelas famílias, pelo Estado e pelos próprios alunos, considerando o estudante como ser fundamental do processo educativo e construindo relações interpessoais em que os conflitos sejam situações de crescimento, e não de perda do equilíbrio no ambiente escolar.

\section{A práxis do orientador educacional perpassada pela mediação dos conflitos e restauração do equilíbrio}

Cumpre ressaltar que a Lei $\mathrm{n}^{\circ} 13.185 / 2015$ sugere como via de combate à intimidação sistemática (bullying) "[...] evitar, tanto quanto possível, a punição dos agressores, privilegiando mecanismos e instrumentos alternativos que promovam a efetiva responsabilização e a mudança de comportamento hostil" (BRASIL, 2015, s/p), ampliando o horizonte para que as práticas restaurativas 
sejam efetivadas nas escolas, substituindo o tradicional modelo em que se figura a punição com pouca eficácia, no que se refere à adoção de posturas de respeito e tolerância para com o próximo.

Deixar ou esperar que o tempo se encarregue de curar os conflitos sem propor ações de reparação ou punição é compactuar com os atos de incivilidade e violência dentro da escola. É por isso que procurar conhecer e oferecer à comunidade educativa outras formas não violentas e que não sejam apenas punitivas para resolução de conflitos é se colocar em um caminho para prevenir violências, como o bullying.

E mais, esses instrumentos alternativos "[...] poderão ter um efeito positivo na escola, promovendo a utilização de métodos positivos de comunicação que visam à transformação do modo como as partes lidam entre si” (MORGADO; OLIVEIRA, 2009, p. 45).

Por esse ângulo, a mediação se apresenta como alternativa viável e tem adentrado o universo escolar como possibilidade de propor a resolução do conflito por meio do auxílio de uma terceira parte, com o objetivo de favorecer o diálogo entre as partes conflitantes. Por sua própria função, o orientador educacional ocupa-se diariamente de grande parte dos conflitos escolares, de modo que precisa agir como mediador quando da discordância entre alunos, alunos e professores, família e escola.

Morgado e Oliveira (2009, p. 49) entendem que a mediação como um "[...] processo de resolução de conflito, não litigioso e baseado no consenso, é propício ao desenvolvimento de soluções criativas, preservando a relação entre as partes em conflito".

Nascimento et al. (2007, p. 21) a definem como um "[...] processo em que os participantes têm a possibilidade de repensar os seus conflitos e buscar opções para os seus problemas através do diálogo, facilitado pela assistência de um terceiro, chamado de mediador". Ainda ampliam o conceito de mediação, acrescentando:

[...] administrar conflitos, diminuir a violência, criar uma cultura de paz, melhorar as relações humanas, gerar possibilidades de crescimento individual e comunitário, garantir direitos, enfim, tornar efetivo o acesso à justiça, em seu mais amplo sentido (NASCIMENTO et al., 2007, p. 22).

Chrispino (2007, p. 23) complementa dizendo que a “[...] mediação induz atitudes de tolerância, responsabilidade e inciativa individual que podem contribuir para uma nova ordem social". Ao conduzir o processo de diálogo entre as partes conflitantes, "promove a reconstrução do conflito, a partir do deslocamento das posições individuais, promovendo também, com sua atuação, novas formas de construção da cidadania” (NASCIMENTO et al., 2007, p. 31). 
Acrescenta-se que o mediador, no contexto escolar, é aquele que produz laços entre os segmentos existentes dentro da escola, gerando o diálogo tão importante nos processos de mediação, pois, quando conversa, abre-se caminho para se restaurar o equilíbrio quebrado por atos de violência.

Como aponta Nascimento et al. (2007, p. 22), “a mediação é um fazer prático, cotidiano, que se aprimora no dia a dia do mediador, a quem não devem faltar ouvidos atentos para a escuta, criatividade para animar os diálogos e, sobretudo, sensibilidade para compreender os conflitos". Retoma-se, assim, um dos pilares da educação, proposto por Delors et al. (1998), que é o aprender a conviver, isto é, o desenvolvimento de "[...] competências e capacidades para a resolução de problema de uma forma positiva, através do diálogo" (MORGADO; OLIVEIRA, 2009, p. 53), o que está de acordo com o expressado por Chrispino (2007, p. 24), quando diz que "[...] não podemos esperar que os estudantes se comportem de um modo disciplinado se não possuem as habilidades para fazê-lo". Dessa forma, há de educar para a escuta, para a comunicação assertiva, buscando auxílio de um mediador.

A opção pela resolução de forma não violenta dos conflitos, utilizando-se da mediação de um terceiro imparcial, não significa que a parte mais fraca irá ceder e se resignar diante do embate; pelo contrário, favorece-se que a parte mais fraca tenha a possibilidade de comunicar os próprios sentimentos e ideias provocadas pelas divergências, de ser ouvida e também de entender aquele que estiver na condição de opressor. Segundo Muszkat (2005, p. 93),

[...] quando alguém nos escuta com atenção, abstendo-se de julgamentos, críticas e opiniões, pode despertar em nós algo surpreendentemente novo, capaz de transformar uma situação aparentemente impossível numa nova possibilidade, despertando nossa disposição e coragem de negociar possíveis interesses e necessidades.

A principal ferramenta do mediador e, portanto, do orientador educacional na resolução de conflitos escolares diretamente é "[...] a escuta imparcial (sem tomar partido) que permite que a história contada seja respeitada na sua singularidade" (NASCIMENTO et al., 2007, p. 29).

Segundo Arruda (2003, p. 352 apud NASCIMENTO et al., 2007, p. 29), "escutar é dar dignidade a uma experiência humana, é incluir, fazer pertencer com sua história e como, em espiral, realimentá-la do ponto de vista social e da cidadania".

Assim, o mediador auxilia as partes em desacordo a olhar para si, para os próprios sentimentos, e não para o conflito, posto que a mediação incentiva "o reconhecimento do outro enquanto pessoa e ser total" (MORGADO; OLIVEIRA, 2009, p. 49). A pessoa é mais importante diante de uma situação de conflito. É ela quem deverá ser preservada e respeitada em sua totalidade. Mas como reagir diante de situações em que se rompeu o equilibrio no ambiente escolar? Nesse sentido, discutem-se as contribuições das práticas restaurativas no ambiente escolar. 


\section{As práticas restaurativas no âmbito escolar}

Já se afirmou que a escola é inserida em um contexto específico, que sofre com tensões advindas de fora de seu ambiente, mas que também provoca tensões entre os sujeitos envolvidos no processo educativo. Assim, de indisciplina ao desrespeito para com professores, perpassando por atos de bullying, depredação de patrimônio às agressões físicas, como proceder?

Semelhante ao adotado nos sistemas de justiça mundo afora, em que aquele que praticou algum mal deve pagar pelo ato no intuito de não voltar a cometê-lo, as escolas também possuem seus regimentos em que, normalmente, situações de indisciplina e/ou violência são resolvidas por meio da punição. Todavia, percebe-se que apenas a punição não resolve atos de incivilidade e que estes, muitas vezes, tendem à recorrência.

Um movimento que se iniciou na segunda metade do século XX propõe fazer o inverso e se convencionou chamar de Justiça Restaurativa. Entende-se como alternativa para resolver conflitos “[...] em que não cabe punição. Tem caráter dialógico e inclusivo. Funda-se na autonomia da vontade e na participação de todas as pessoas afetadas direta ou indiretamente pela violência" (CECCON et al., 2009, p. 139).

Cumpre acrescentar que esse modelo não é mais uma forma de justiça, senão uma possibilidade de olhar para os atos conflituosos e buscar resolvê-los por meio do respeito, da igualdade e integridade, que não deixa de aplicar uma punição àquele que praticou o ato de incivilidade a fim de que os demais visualizem que houve uma situação desrespeitosa, mas pautado pelo diálogo, sem exposição da pessoa e como processo educativo, cujo fim é a reversão para soluções positivas (MENEZES; GRANZZOTTO, 2008).

Trata-se de um processo em que se cria um círculo restaurativo em torno do agressor e da vítima e para o qual todos devem contribuir, estabelecendo-se, assim, "[...] um plano de ação para que as necessidades de todos os afetados sejam atendidas, com garantia ampla de seus direitos e reconhecimento voluntário das responsabilidades dos envolvidos" (CECCON et al., 2009, p. 139).

Acrescenta-se que a finalidade dos círculos restaurativos é colocar todos aqueles envolvidos "[...] pelo conflito - vítimas, ofensores e comunidade envolvida - como forma de reparar danos, restaurar dignidade, segurança e justiça, e reintegrar todos na sociedade" (BALAGUER, 2014, p. 271).

No círculo restaurativo, há um olhar diferenciado para a pessoa ou as pessoas envolvidas, quase que se podendo afirmar ser mais acolhedor no sentindo de preservar a pessoa, punindo sim o ato de incivilidade, mas como processo educativo em que aquele que cometeu o ato participe e até apresente soluções para a restauração do equilíbrio. 
Ainda embasado na contribuição de Ceccon et al. (2009), recorda-se que conflitos escolares mal administrados resultam em demonstrações de violência e, consequentemente, em punições, as quais acabam por diminuir os laços de pertencimento. Com isso, a conexão com a escola se rompe, contribuindo para que novos conflitos surjam, para que o equilíbrio se quebre e novas formas de violência de manifestem. Em outras palavras, instaura-se um círculo vicioso e não educativo diante dos conflitos.

Assim, o caminho para uma escola restaurativa consiste em centralizar o foco na pessoa, seja o estudante, seja o professor ou pais. A pessoa e suas expectativas devem estar sempre em vista, buscando a interação entre as partes, o desenvolvimento e o exercício da disciplina como autodomínio e a visão de que os conflitos são oportunidades de crescimento.

Diferentemente da mediação em que normalmente o conflito é originado entre duas partes e resolvido com a presença do mediador quando uma parte oferece a restauração do mal, o círculo restaurativo propicia o engajamento de outras pessoas que se configuram com uma rede de pessoas mobilizadas em prol da resolução dos problemas (CECCON et al., 2009).

Justamente para se precaver de um mal maior que Chrispino e Chrispino (2008) alertam que, cada vez mais, os conflitos escolares acabam por ser resolvidos em instância judicial, em uma clara demonstração de que a escola está perdendo o controle no manejo dos conflitos ocorridos em seu espaço. Ainda, segundo os autores $(2008$, p. 26), a restauração do equilíbrio dentro da escola é de responsabilidade dos "[...] professores e os gestores educacionais de todos os níveis e, como aliadas, as famílias e seus filhos".

Em outras palavras, o conflito não é para ser resolvido por alguém de fora, como um juiz ou advogado, mas pelas partes litigantes. E qual é a melhor forma para isso? Freire (2014) já apontou o caminho: o diálogo. É por meio do diálogo, “[...] ou melhor, da rememoração da história do conflito, que se pode produzir uma restauração das relações, afetos, traumas e feridas provocadas por ele” (MORRISON, 2010 apud BALAGUER, 2014, p. 270).

Por sua função, o orientador educacional tem a autoridade delegada por parte da escola e das famílias, e dos próprios estudantes, para conduzir ações que favoreçam o equilíbrio na escola. Para isso, precisa sair de sua sala e se colocar à escuta dos estudantes, dos professores e das famílias. Nesse caminho dialógico, esse profissional ficará mais perto, será o educador de referência para os estudantes e professores, propiciando uma solução que tenha a mediação e restauração, e não a punição, no cerne do projeto político-pedagógico.

É fato que, na escola punitiva ou restaurativa, a resolução dos conflitos não é de exclusividade do orientador educacional. Há de se tecer uma rede de relações fortalecidas pelo senso de pertencimento, em que o diálogo entre professores, gestores, famílias, estudantes seja potencializado em todos os níveis em busca da restauração do equilíbrio e do cultivo de uma cultura de paz. 
A resolução de forma não violenta dos conflitos é uma necessidade que se estende para além dos muros da escola. Ao eleger a mediação e a restauração como alternativa para superar os conflitos e chegar a uma escola cujo equilíbrio é alcançado pelo engajamento de todos, é estendê-la para além de "um método de administração de conflitos, como um valioso modo de concepção de vida, pautada no diálogo e na cultura de paz" (NASCIMENTO et al., 2007, p. 22).

Tudo isso é o que se espera constituir na escola: uma cultura de paz. Sabe-se que a paz não é a ausência de conflitos, mas o constante equalizar de expectativas pessoais ou coletivas por meio de diálogo. A paz gerada e fortificada pelo senso de que a escola é a soma do contributo de cada pessoa que passa por ela, deixando um pouco de si e levando consigo um tanto de valores humanos.

\section{Considerações finais}

O orientador educacional, por especificação de seu cargo, é parte da equipe gestora da escola, ou seja, contribui ao lado do coordenador pedagógico e do diretor para que a escola funcione de acordo com o estabelecido pelo projeto político-pedagógico - claro que cada profissional em sua área mais específica: o orientador, especialmente, com os alunos e famílias; o coordenador mais próximo dos professores; e o diretor no comando geral da escola.

Assim, a maneira que o orientador educacional pode contribuir para que a comunidade educativa aprenda a lidar com os conflitos e resolvê-los de forma não violenta é suscitar a reflexão, continuadamente, acerca dos temas "conflito", "indisciplina", "mediação", "círculos restaurativos", aproveitando os momentos de reuniões pedagógicas, reuniões de pais, de encontro com os estudantes para falar sobre eles.

Individualmente, pode também colocar-se à disposição para orientar os professores em como agir em situações específicas de conflitos com os estudantes, ensinando técnicas de mediação e de comunicação assertiva, de restauração do equilíbrio, propiciando material de aprofundamento sobre os assuntos e indicando cursos promovidos na área, como os de círculo restaurativo e mediação.

No que tange à transição da escola punitiva para a restaurativa, o orientador educacional terá que cultivar a escuta de cada estudante, seja o autor de atos incivilizados, seja a vítima destes, de forma imparcial. Deve ainda ser capaz de fomentar que ambas as partes avaliem os sentimentos advindos do conflito e que possam agir sobre os sentimentos, superando o momento de tensão.

Todavia, o orientador ainda será cobrado para que reprima ou puna quando um estudante lhe for encaminhado por motivo de indisciplina ou violência. Mas, diante disso, há de se esclarecer aos envolvidos que o ato indisciplinado ou violento precisa, sim, ser interrompido, e a pessoa, preservada. É necessário refletir e perceber que o ato praticado é inadequado e adotar nova postura, pois, do contrário, o círculo vicioso de indisciplina/violência-punição-recorrência não cessará. 
Sobre os conflitos escolares, observados no cotidiano de um orientador, os mais recorrentes são aqueles originados das próprias tensões envolvidas no processo de ensino e aprendizagem, tendo como causas escolares, algumas vezes, o uso de métodos por professores que não estimulam os estudantes, os quais, por sua vez, reagem de maneira indisciplinada, causando desgaste entre o professor que quer ensinar e o aluno que não quer aprender daquela forma.

A pouca eficácia da comunicação entre os sujeitos do processo educativo é outra causa de conflito e uma barreira que o orientador tem de auxiliar a comunidade a transpô-la. O orientador educacional precisa comunicar os sentimentos diante dos conflitos, das necessidades não supridas, das expectativas frustradas pela interferência do outro. É por meio de diálogo efetivo e assertivo que se consegue chegar a um consenso e à resolução não violenta dos conflitos.

Outras violências manifestadas no âmbito escolar são xingamentos, agressões físicas, intimidações, comentários maldosos e de cunho pejorativos, fofocas, difamações, calúnias, depreciação virtual, isolamento social, destruição de bens e tantos outros que, quando repetidos e com o uso de força desproporcional, caracterizam-se como bullying.

O bullying é um grande desafio da comunidade educativa, em especial para o orientador, por causa da ampliação na realidade das escolas, que nem sempre estão preparadas para lidar com essa violência em seu próprio espaço, o que abre brecha para que instâncias externas ganhem autoridade para resolvê-las, situação diagnosticada e explicitada por Chrispino e Chrispino (2008), a respeito da crescente judicialização dos conflitos escolares.

Por consequência, estende-se o olhar para as causas externas relacionadas aos conflitos escolares, em que a escola perde, gradualmente, sua autonomia para lidar com as situações que lhe são inerentes, somadas à desvalorização da instituição educativa mediante a depreciação da carreira docente pela sociedade e pelos próprios profissionais, da não clareza dos limites dos estudantes, da pouca habilidade das famílias educarem com os valores básicos para uma relação interpessoal, perpassada por um mínimo de urbanidade.

No dia a dia, chega ao orientador uma quantidade de situações conflituosas que ele precisa resolver. Assim, o orientador exerce o papel de mediador dos conflitos, facilitando que as partes conflitantes que lhe chegam consigam dialogar, instigando um consenso que traga benefício a todos. Busca, por intermédio da cooperação dos estudantes e seus pares, professores, famílias, promover o diálogo para que os conflitos sejam motivos de crescimento, e não de uma longa briga em órgão judicial.

Entretanto, sozinho o orientador educacional gastará suas forças, e os conflitos continuarão a resultar em atos incivilizados e, até mesmo, em violência. $\mathrm{O}$ caminho é convocar todos os sujeitos do processo educativo a assumir, de acordo com seu papel, o compromisso de melhorar as relações humanas que ocorrem no 
interior da escola, a mudar o modo de se relacionar diante de conflitos, a procurar conhecer as causas que geram a indisciplina, a violência o ato incivilizado, e, dessa forma, combater qualquer tipo de indisciplina e violência na escola.

O caminho é adotar a vertente restaurativa que não exclui, mas chama aquele que praticou um ato incivilizado para corrigi-lo com o auxílio de uma ajuda. Com o fim de se chegar a uma escola restaurativa, há de se investir alto em canais de participação, na construção de vínculos de pertencimento, de normas de convivência discutidas e acordadas entre aqueles que deverão vivenciá-las, no desenvolvimento das habilidades sociais de convivência. Com efeito, constituir-se-á uma cultura de paz não pela ausência de conflitos, mas pelo constante equalizar de expectativas pessoais ou coletivas por meio de diálogo. A paz é gerada e fortificada pelo senso de que a escola é a soma da contribuição de cada pessoa que por ela passa, deixando um pouco de si e levando consigo um tanto da escola.

Eis o grande desafio do orientador educacional: demonstrar que o velho paradigma da punição já não é tão eficiente na conjuntura atual e que se devem buscar novos caminhos para resolução não violenta dos conflitos.

Recebido em: 17/07/2017

Revisado pelo autor em: 28/08/2017 Aceito para publicação em: 19/09/2017

\section{Notas}

1 Trabalho de conclusão do curso de pós-graduação lato sensu em Orientação Educacional pela Universidade Católica Dom Bosco (UCDB) em parceria com o Portal Educação.

2 Pós-graduação em Comunicação Empresarial e Marketing pela Universidade de Araraquara (2016). Graduação em Pedagogia pelo Instituto de Educação Superior de Brasília (IESB) (2015). Orientadora educacional de Ensino Fundamental II e Ensino Médio do Centro Educacional Maria Auxiliadora de Brasília. E-mail: escrevaparamalu@gmail.com

3 Mestrado em Educação pela Universidade Católica Dom Bosco (UCDB) (2013). Especializações em Tecnologias em Educação pela Pontifícia Universidade Católica do Rio de Janeiro (PUC-RJ) (2010), em Planejamento em Tutoria em EAD pela Universidade Federal do Mato Grosso do Sul (UFMS) (2008) e em Língua Inglesa pelo Centro Universitário de Campo Grande (UNAES) (2007). Licenciatura em Letras com habilitação em Português/Inglês e respectivas Literaturas pela Universidade para o Desenvolvimento do Estado e da Região do Pantanal (UNIDERP) (2002). Orientadora de trabalho de conclusão do curso de pós-graduação em Orientação Educacional pela UCDB em parceria com o Portal Educação. E-mail: anaribasprof@gmail.com

\section{Referências}

BALAGUER, Gabriela. As práticas restaurativas e suas possibilidades na escola: primeiras aproximações. Revista Subjetividades, Fortaleza, v. 14, n. 2, p. 266275, 2014. 
BRASIL. Lei no 12.014, de 6 de agosto de 2009. Altera o art. 61 da Lei no 9.394, de 20 de dezembro de 1996, com a finalidade de discriminar as categorias de trabalhadores que se devem considerar profissionais da educação. Diário Oficial [da] União, Brasília, DF, 7 ago. 2009. Disponível em: <http://www.planalto. gov.br/ccivil_03/_Ato2007-2010/2009/Lei/L12014.htm\#art1>. Acesso em: 4 de set de2017.

. Lei no 13.185, de 6 de novembro de 2015. Institui o Programa de Combate à Intimidação Sistemática (Bullying). Diário Oficial [da] União, Brasília, DF, 9 nov. 2015. Disponível em: < http://www.planalto.gov.br/ccivil_03/_ Ato2015-2018/2015/Lei/L13185.htm>. Acesso em: $1^{\text {o }}$ ago. 2016.

CECCON, Claudius et.al. Conflitos na escola: modos de transformar. Dicas para refletir e exemplos de como lidar. São Paulo: CECIP/Imprensa Oficial do Estado de São Paulo, 2009.

CHRISPINO, Álvaro. Gestão do conflito escolar: da classificação dos conflitos aos modelos de mediação. Ensaio: Avaliação e Políticas Públicas em Educação, Rio de Janeiro, v. 15, n. 54, p. 11-28, 2007.

CHRISPINO, Álvaro; CHRISPINO, Raquel. A judicialização das relações escolares e a responsabilidade civil dos educadores. Ensaio: Avaliação e Políticas Públicas em Educação, Rio de Janeiro, v. 16, n. 58, p. 9-30, jan./mar. 2008.

DELORS, Jacques et al. Educação: um tesouro a descobrir. Relatório para a Unesco pela Comissão Internacional sobre Educação para o século. São Paulo: Cortez; Brasília: MEC/UNESCO, 1998.

FREIRE, Paulo. Educação e mudança. São Paulo: Editora Paz e Terra, 2014.

LONGO, Maristela; PEREIRA, Zelandia Cecconi. O papel do orientador educacional na promoção do relacionamento interpessoal entre alunos e professores contribuindo no processo ensino aprendizagem. Perspectiva, Erechim, v. 35, n. 132, p. 183-196, dez. 2011. Disponível em: <http://www.uricer.edu.br/ site/pdfs/perspectiva/132_243.pdf>. Acesso em: 2 out. 2016.

MEIRELES, Cecília. Ou isto ou aquilo. 25. ed. Rio de Janeiro: Nova Fronteira, 1990.

MENEZES, Cristiane Penning Pauli de; GRANZZOTTO, Daiane Stradiotto. Bullying escolar: a justiça restaurativa como forma de enfrentar e prevenir violências. REGAE - Revista de Gestão e Avaliação Educacional, Santa Maria, v. 4, n. 8, p. 51-57, jul./dez. 2015. Disponível em: <https://periodicos.ufsm.br/ regae/article/view/16523/pdf $>$. Acesso em: 20 jun. 2016. 
MORGADO, Catarina; OLIVEIRA, Isabel. Mediação em contexto escolar: transformar o conflito em oportunidade. Exedra, n. 1, p. 43-56, 2009. Disponível em <http://www.exedrajournal.com/docs/01/43-56.pdf > . Acesso em: 25 jul. 2016.

MUSZKAT, Malvina Ester. Guia prático de mediação de conflitos: em famílias e organizações. São Paulo: Summus Editorial, 2005.

NASCIMENTO, André Luís et al. Guia de mediação popular. Salvador: Juspopuli, 2007.

RAIMUNDI, Ana Carolina. Casos de bullying nas escolas cresce no Brasil. Jornal Hoje, Rio de Janeiro, 26 ago. 2016. Disponível em: <http://g1.globo.com/ jornal-hoje/noticia/2016/08/casos-de-bullying-nas-escolas-cresce-no-brasil-diz-pesquisa-do-ibge.html>. Acesso em: 26 ago. 2016.

VASCONCELOS, Celso dos Santos. Os desafios da indisciplina na sala de aula e na escola. São Paulo: FDE, 1997. (Série Ideias, n. 28). Disponível em: <http://www.crmariocovas.sp.gov.br/pdf/ideias_28_p227-252_c.pdf> Acesso em: 3 out. 2016. 